\title{
The Comprehensive Analysis of Traumatic Rib Fractures and their Complications: A Post Mortem Study
}

\author{
Vijay Kumar AG ${ }^{1 *}$, Shivaramu MG¹, Kumar U1', Shridhar KC ${ }^{1}$, Ajay Kumar TS² and Vinay. R. Hallikeri ${ }^{3}$
}

${ }^{1}$ Department of Forensic Medicine \& Toxicology, Adichunchanagiri ,Institute of Medical Sciences, Mandya, Karnataka State, India

${ }^{2}$ Department of Forensic Medicine \& Toxicology, Sri Devaraj Urs Medical College, kolar, Karnataka State, India

${ }^{3}$ Post Graduate, Dept. of Forensic Medicine \& Toxicology, KLE University's J.N.Medical College, Belgaum, Karnataka, India

\begin{abstract}
Introduction: Rib fractures are the most common injury sustained following blunt chest trauma, accounting for more than half of thoracic injuries from non-penetrating trauma. Approximately $10 \%$ of all patients admitted after blunt chest trauma have one or more rib fractures [1]. In United States they account for $10 \%$ of traumatic injuries and $14 \%$ of all chest wall injuries. The incidence of flail chest is $10 \%$ to $15 \%$ of severe chest traumas [2].

Material and Methods: In this retrospective study, fatal cases of thoracic trauma autopsied during the period 1st January 2009 to 31st December 2010 were analyzed at the Department of Forensic Medicine \& Toxicology, Adichunchanagiri Institute of Medical Sciences, Mandya District, Karnataka, India.

Results: In the present study, $31.3 \%$ of victims belong to the $3^{\text {rd }}$ decade of life. Women were less involved than men with ratio of $1: 1.5$. The mortality rate was $20.18 \%$. The victims in most of the cases sustained non displaced rib fractures followed by displaced fractures. $5^{\text {th }}$ rib fracture were seen in eight cases followed by $4^{\text {th }}$ and $6^{\text {th }}$ ribs fracture were seen in seven cases. The nature of death in most of the cases was accidental. The victims in most of the cases sustained road traffic accidental injuries followed by fall from height. Haemo-thorax was found in 27 cases and pneumo-thorax was seen in 20 cases.

Discussion: In the study done by Mehmet [3]. 548 (38.7\%) of the cases had rib fractures. There were 331 males and 217 females, with an overall mean age of 43 years (range: 5-78 years), the etiology of the trauma included road traffic accidents in 330 cases, falls in 122, assault in 54, and industrial accidents in 42 cases. Pulmonary complications such as pneumo-thorax $(37.2 \%)$, hemo-thorax $(26.8 \%)$, hemo-pneumothorax $(15.3 \%)$, pulmonarycontusion (17.2\%), flail chest (5.8\%) and isolated subcutaneous emphysema (2.2\%) were noted [3].

Conclusions: A rib fracture secondary to blunt thoracic trauma is an important indicator of the severity of the trauma. In the present study we explored the morbidity and mortality rates in patients with rib fractures. Finally, we come to a conclusion that blunt trauma patients sustaining more number of fractured ribs are always associated with higher mortality and morbidity rates owing to greater severity of internal organ injuries.
\end{abstract}

Keywords: Thoracic trauma; Rib fracture; Pneumo-thorax; Haemothorax

\section{Introduction}

A rib fracture is disruption in any of the 12 rib bones that form the rib cage. The disruption may be a single fracture of one rib, a single fracture of multiple ribs, or a rib or ribs may be broken into several pieces (comminuted fracture). The fourth through ninth ribs are the most commonly fractured, and fractures of the eighth through twelfth ribs are often a marker for abdominal organ injuries. Rib fractures are the most common injury sustained following blunt chest trauma, accounting for more than half of thoracic injuries from nonpenetrating trauma. Approximately $10 \%$ of all patients admitted after blunt chest trauma have one or more rib fractures [1].

\section{Incidence}

In the United States they account for $10 \%$ of traumatic injuries and $14 \%$ of all chest wall injuries. The incidence of flail chest is $10 \%$ - $15 \%$ of severe chest traumas. Overall in the world the prevalence of rib fractures is linked to the prevalence of the underlying cause of the trauma. Rib fractures are more common in countries with higher incidence of motor vehicle accidents. Mortality/ morbidity correlates with the number of rib fractures and degree of injury to underlying structures [2].

\section{Risk}

Individuals at risk for chest trauma from work, recreational or athletic pursuits are more likely to sustain a rib fracture. $72 \%$ of rib fractures occur in men, possibly due to job requirements for heavy labor or participation in sport activities that create a greater risk for blunt trauma. Multiple rib fractures will often be associated with an underlying pulmonary contusion, which may not be immediately apparent on an initial chest X-ray. Fractures of the lower ribs may be associated with diaphragmatic tears and spleen or liver injuries [3].

\section{Material and Methods}

In this retrospective study, fatal cases of thoracic trauma autopsied

*Corresponding author: Vijay Kumar AG, Department of Forensic Medicine \& Toxicology, Adichunchanagiri Institute of Medical Sciences, Mandya, Karnataka State, India, E-mail: vijay.fmt@rediffmail.com

Received September 21, 2011; Accepted October 07, 2011; Published Octobe 15,2011

Citation: Vijay Kumar AG, Shivaramu MG, Kumar U, Shridhar KC, Ajay Kuma TS (2011) The Comprehensive Analysis of Traumatic Rib Fractures and their Complications: A Post Mortem Study. J Forensic Res S2:004. doi:10.4172/21577145.S2-004

Copyright: (c) 2011 Vijay Kumar AG, et al. This is an open-access article distributed under the terms of the Creative Commons Attribution License, which permits unrestricted use, distribution, and reproduction in any medium, provided the original author and source are credited. 
during the period $1^{\text {st }}$ January 2009 to 31 st December 2010 were analyzed at the Department of Forensic Medicine \& Toxicology, Adichunchanagiri Institute of Medical Sciences, Mandya District, Karnataka, India.

During this study several epidemiological observations and their results have been considered including the details about the type, nature and frequency of rib fractures and their complications.

\section{Results}

Table 1: In the present study, $31.3 \%$ of victims belong to the $3^{\text {rd }}$ decade of life. Women were less involved than men with ratio of 1: 1.5.

Table 2: According to this study the mortality rate in rib fracture cases was $20.18 \%$.

Table 3: The victims in most of the cases sustained non displaced rib fractures ( 37 cases; $55.2 \%$ ) followed by displaced fractures (18 cases; $26.9 \%)$.

Table 4: $5^{\text {th }}$ rib fracture were seen in 8 cases followed by $4^{\text {th }}$ and $6^{\text {th }}$ ribs fracture were seen in 7 cases.

Table 5: Nature of death in most of the cases were accidental (44 cases; $65.7 \%$ ).

Table 6: The victims in most of the cases sustained road traffic accidental injuries (39 cases; 58.2\%) followed by fall from height (18 cases; $26.8 \%$ ).

Table 7: Haemo-thorax was found in 27 cases (40.3\%) and pneumo-thorax was seen in 20 cases (29.9\%).

\section{Discussion}

In the present study, $31.3 \%$ of victims belong to the $3^{\text {rd }}$ decade of life. Women were less involved than men with ratio of 1: 1.5. The victims in most of the cases sustained non displaced rib fractures (37 cases; $55.2 \%$ ) followed by displaced fractures (18 cases; $26.9 \%$ ). In the study done by Mehmet. [3] 548 (38.7\%) of the cases had rib fractures. There were 331 males and 217 females, with an overall mean age of 43 years(range:5-78 years)[3].

\begin{tabular}{|l|l|l|l|l|l|l|}
\hline Age group & Male & $\%$ & Female & $\%$ & Total & $\%$ \\
\hline$<10$ & 00 & 00 & 00 & 00 & 00 & 00 \\
\hline $11-20$ & 05 & 12.5 & 04 & 14.8 & 09 & 13.4 \\
\hline $21-30$ & 12 & 30.0 & 09 & 33.3 & 21 & 31.3 \\
\hline $31-40$ & 09 & 22.5 & 06 & 22.2 & 15 & 22.4 \\
\hline $41-50$ & 08 & 20.0 & 05 & 18.5 & 13 & 19.4 \\
\hline$>60$ & 06 & 15.0 & 03 & 11.1 & 09 & 13.4 \\
\hline Total & $\mathbf{4 0}$ & $\mathbf{1 0 0}$ & $\mathbf{2 7}$ & $\mathbf{1 0 0}$ & $\mathbf{6 7}$ & $\mathbf{1 0 0}$ \\
\hline
\end{tabular}

Table 1: Distribution of cases according to age and sex.

Total no. of rib fractures cases admitted in the hospital between 332 January 2009 to 31 December 2010

Total no. of rib fractures cases autopsied in the hospital between 67 January 2009 to 31 December 2010

percentage $20.18 \%$

Table 2: Total number of rib fractures cases admitted in the hospital.

\begin{tabular}{|l|l|l|}
\hline type of rib fractures & No. of cases & $\%$ \\
\hline Non-displaced rib fracture & 37 & 55.2 \\
\hline Displaced rib fracture & 18 & 26.9 \\
\hline Comminuted rib fracture & 12 & 17.9 \\
\hline Total & $\mathbf{6 7}$ & $\mathbf{1 0 0}$ \\
\hline
\end{tabular}

Table 3: Distribution of cases according to type of rib fractures.

\begin{tabular}{|l|l|l|}
\hline ribs & $\begin{array}{l}\text { side of rib fractures } \\
\text { Right side }\end{array}$ & Left side \\
\hline $1^{\text {st }}$ rib & 0 cases & 0 cases \\
\hline $2^{\text {td }}$ rib & 1 cases & 0 cases \\
\hline $3^{\text {rd }}$ rib & 2 cases & 2 cases \\
\hline $4^{\text {th }}$ rib & 4 cases & 3 cases \\
\hline $5^{\text {th }}$ rib & 4 cases & 4 cases \\
\hline $6^{\text {th }}$ rib & 3 cases & 4 cases \\
\hline $7^{\text {th }}$ rib & 2 cases & 3 cases \\
\hline $8^{\text {th }}$ rib & 1 cases & 1 cases \\
\hline $9^{\text {th }}$ rib & 1 cases & 1 cases \\
\hline $10^{\text {th }}$ rib & 0 cases & 1 cases \\
\hline $11^{\text {th }}$ rib & 1 cases & 1 cases \\
\hline $12^{\text {th }}$ rib & 1 cases & 0 cases \\
\hline
\end{tabular}

Table 4: Distribution of cases according to side of rib fractures.

\begin{tabular}{|l|l|l|}
\hline Nature of death & No. of cases & $\%$ \\
\hline Accidental & 44 & 65.7 \\
\hline Homicidal & 13 & 19.4 \\
\hline Suicidal & 10 & 14.9 \\
\hline Total & 67 & 100 \\
\hline
\end{tabular}

Table 5: Distribution of cases according to nature of death.

\begin{tabular}{|l|l|l|}
\hline Manner of death & No. of $\quad$ cases & $\%$ \\
\hline Road traffic injuries & 39 & 58.2 \\
\hline Fall from height & 18 & 26.8 \\
\hline Injuries by blunt weapon & 06 & 08.9 \\
\hline Stab injuries & 04 & 05.9 \\
\hline Total & $\mathbf{6 7}$ & $\mathbf{1 0 0}$ \\
\hline
\end{tabular}

Table 6: Distribution of cases according to manner of death.

\begin{tabular}{|l|l|l|}
\hline Pleural cavity & No. of cases & $\%$ \\
\hline Normal & 07 & 10.5 \\
\hline Haemo-thorax & 27 & 40.3 \\
\hline Pyo-thorax & 13 & 19.4 \\
\hline Pneumo-thorax & 20 & 29.9 \\
\hline Total & $\mathbf{6 7}$ & $\mathbf{1 0 0}$ \\
\hline
\end{tabular}

Table 7: Distribution cases according to condition of pleural cavity.

In the present study, $5^{\text {th }}$ rib fracture were seen in eight cases followed by $4^{\text {th }}$ and $6^{\text {th }}$ ribs fracture were seen in seven cases. Nature of death in most of the cases was accidental (44 cases; 65.7\%). The victims in most of the cases sustained road traffic accidental injuries (39 cases; $58.2 \%$ ) followed by fall from height (18 cases; $26.8 \%$ ). Haemo-thorax was found in 27 cases $(40.3 \%)$ and pneumo-thorax was seen in 20 cases (29.9\%). In the study done by Mehmet. [3] the etiology of the trauma included road traffic accidents in 330 cases, falls in 122, assault in 54, and industrial accidents in 42 cases. Pulmonary complications such as pneumo-thorax (37.2\%), hemo-thorax (26.8\%), hemo-pneumothorax(15.3\%),pulmonary-contusion(17.2\%), flail chest (5.8\%) and isolated subcutaneous emphysema (2.2\%) were noted [3] .

In the present study the mortality rate was $20.18 \%$. In the study done by Ziegler DW and Agarwal NN [4] on patients with rib fractures, the mortality rate reached $12 \%$; of these, $94 \%$ had associated injuries and $32 \%$ had a hemo-thorax or a pneumothorax. [4] In the study done by Lotfipour. [5] on 99 elderly patients, $16 \%$ of patients developed adverse events, including 2 deaths. [5] Rib fractures are the most common injury in elderly blunt chest trauma patients, and each additional rib fracture increases the odds of dying by $19 \%$ and of developing pneumonia by $27 \%[6,7]$. 
Citation: Vijay Kumar AG, Shivaramu MG, Kumar U, Shridhar KC, Ajay Kumar TS (2011) The Comprehensive Analysis of Traumatic Rib Fractures and their Complications: A Post Mortem Study. J Forensic Res S2:004. doi:10.4172/2157-7145.S2-004

Page 3 of 3

\section{Conclusions}

A rib fracture secondary to blunt thoracic trauma is an important indicator of the severity of the trauma. In the present study we explored the morbidity and mortality rates in patients with rib fractures. Finally, we come to a conclusion that blunt trauma patients sustaining more number of fractured ribs are always associated with higher mortality and morbidity rates owing to greater severity of internal organ injuries.

\section{Competing Interests}

The authors declare that they have no competing interests. Both authors have read and approved the final manuscript.

\section{References}

1. Colosimo AJ, Byrne E, Heidt RS Jr, Carlonas RL, Wyatt H (2004) Acute traumatic first-rib fracture in the contact athlete: a case report. Am J Sports Med 32: 1310-1312.

2. Nadalo, Lennard A and Kory J. "Rib, Fractures."

3. Mehmet S, Hasan T, Salih T, Erkmen G, Ulku Y, et al. (2003) A comprehensive analysis of traumatic rib fractures: morbidity, mortality and management. Eur $J$ Cardiothorac Surg 24: 133-138.

4. Ziegler DW, Agarwal NN (1994) The morbidity and mortality of rib fractures. J Trauma 37: 975-979.

5. Lotfipour S, Kaku SK, Vaca FE, Patel C, Anderson CL, et al. (2009) Factors associated with complications in older adults with isolated blunt chest trauma. West J Emerg Med 10: 79-84.

6. Bulger EM, Arneson MA, Mock CN, Jurkovich GJ (2000) Rib fractures in the elderly. J Trauma 48:1040-1046; discussion 1046-1047.

7. Shorr RM, Rodriguez A, Indeck MC, Crittenden MD, Hartunian S, et al. (1989) Blunt chest trauma in the elderly. J Trauma 29: 234-237. 